\title{
REVISÃO BIBLIOGRÁFICA DAS PUBLICAÇÕES ACADÊMICAS SOBRE A CRIANÇA NA PERSPECTIVA FENOMENOLÓGICA
}

\author{
Bibliographic Review of Academic Publications about Children in the \\ Phenomenological Perspective \\ Revisión Bibliográfica de Publicaciones Académicas Sobre los Niños desde una \\ Perspectiva Fenomenológica
}

\author{
Elisa Smile Teixeira de Oliveira \\ Amanda Acco Rosa \\ JOANNELIESE DE LUCAS FREITAS
}

\begin{abstract}
Resumo: A Psicologia tem estudado a infância a partir do olhar adulto, como uma etapa do desenvolvimento humano. A perspectiva fenomenológica contribui de forma significativa para se estudar e abordar o fenômeno infantil a partir da própria criança, fora do olhar desenvolvimentista. O presente trabalho se constitui como uma revisão sistemática de literatura sobre os estudos fenomenológicos da criança e da infância. Foram realizadas buscas nos portais PePSIC, SciELO, Portal CAPES e BVS Salud Bireme. Foram analisados 20 artigos, publicados entre 2005 e 2015. A área da Psicologia e da Filosofia apresentam o maior volume de trabalhos. Constatou-se um maior número de estudos teóricos, apontando para uma necessidade de incremento de estudos empíricos que se voltem à experiência própria da criança. O autor mais citado foi Merleau-Ponty, seguido de Heidegger e Husserl. Foram encontradas diversas compreensões de criança, sendo que predominam as leituras existenciais, compreendendo a infância fora de uma perspectiva desenvolvimentista.
\end{abstract}

Palavras-chave: Criança; Infância; Fenomenologia; Psicologia; Desenvolvimento.

Abstract: Psychology has been studying childhood from an adult viewpoint as a stage of human development. The phenomenological perspective contributes significantly in the childhood phenomenon study doing it from the child's perspective, rather than the developmental one. The present work constitutes a systematic review of literature about the phenomenological studies of children and childhood. Data was collected through the following databases: PePSIC, SciELO, Portal CAPES and BVS Salud Bireme. Twenty articles were analyzed, which were published between 2005 and 2015. The areas of Psychology and Philosophy had the largest volume of papers. Most papers were theoretical, pointing to a need for more empirical studies, especially from the child's viewpoint. The most cited author was Merleau-Ponty, followed by Heidegger and Husserl. Among several comprehensions of childhood found the majority were existentialists, dissenting from the developmental perspective about the infancy.

Keywords: Child; Childhood; Phenomenology; Psychology; Development.

Resumen: La psicología ha estudiado la infancia desde la mirada adulta, como una etapa del desarrollo humano. La perspectiva fenomenológica contribuye de manera significativa en lo estudio y en la abordagen del fenómeno de la infancia desde la perspectiva propia del niño, en oposición a la mirada desarrollista. Este trabajo es una revisión sistemática de la literatura sobre los estudios fenomenológicos de los niños y de la infancia. Se realizaron búsquedas en portales PePSIC, SciELO, Portal Capes y BVS Salud Bireme. 20 artículos publicados entre 2005 y 2015 fueron analizados. Las áreas de la psicología y de la filosofía presentaran el mayor volumen de trabajos. Se encontró un mayor número de estudios teóricos, que apunta a la necesidad de aumentar los estudios empíricos que adopten una perspectiva desde la propia experiencia del niño. El autor más citado fue Merleau-Ponty, seguido de Heidegger y Husserl. Se encontraron diferentes concepciones de los niños, siendo las lecturas existenciales las predominantes, que comprenden la infancia en una perspectiva diversa de la desarrollista.

Palavras-clave: Niño; Infancia; Fenomenología; Psicología; Desarrollo.

\section{Introdução}

Estudar a criança e a infância contribui para a compreensão de suas especificidades e experiências, possibilitando novas práticas e olhares. No campo da Psicologia, a criança tem sido compreendida a partir de um olhar desenvolvimentista, que descreve o que se espera que lhe aconteça, a fim de que se torne um adulto realizado (Freitas, 2015). As ciências da natureza contribuíram funda- mentalmente para essa visão biológico-evolucionista que desconsidera o caráter histórico e social da infância. Este período da vida humana é entendido, portanto, como uma etapa que se conclui depois de certo tempo, sendo que o tempo transcorreria de modo linear, homogêneo e cumulativo (Souza, 1996). Dessa forma, sob a ótica da psicologia do desenvolvimento, a infância é entendida como "mero estado de passagem, precário e efêmero, que caminha para sua resolução posterior na idade adulta, 
por meio da acumulação de experiências e conhecimento" (Souza, 1996, p. 44).

A metodologia fenomenológica prevê um retorno "às coisas mesmas", tal como elas se apresentam na experiência vivida, o que tornaria possível a exploração da experiência própria da criança a partir de seu ponto de vista e não mais desde perspectivas que são, nada mais, nada menos, que a teorização da experiência da criança desde o ponto de vista e da condição do adulto. Merleau-Ponty (2002; 2006) tece críticas à abordagem desenvolvimentista, apontando seus problemas e prejuízos, os quais intensificam nossa dificuldade de entender o fenômeno infantil desde si mesmo, desde seus modos próprios de aparição. Para o filósofo, a visão evolucionista reduz a criança a um sujeito incompleto e inacabado que, ao chegar à idade adulta, estaria "formado" e "realizado" como humano. Todavia, argumenta, à criança nada falta em comparação ao adulto, possuindo papel ativo em suas relações no mundo circundante.

Embora o método fenomenológico seja uma ferramenta que nos auxilie na aproximação da criança e de sua vivência, há na experiência infantil uma certa opacidade para o adulto - o que caracteriza as pesquisas sobre a infância e com crianças, como desafiadoras, mesmo em fenomenologia, pois, como podemos estudar a criança em sua condição própria, sendo adultos? (Freitas, 2015; Allen, 1976). De qualquer modo, pensar a infância tendo como ponto de partida a própria experiência infantil, para além do olhar desenvolvimentista, se torna um desafio não apenas para a fenomenologia, como também para as ciências humanas, especialmente a psicologia.

Assim como os adultos, a criança mantém relação com a cultura e com o outro e, mais além, ela se realiza no mundo, ela é no mundo. Sua experiência está relacionada, a todo tempo, com o mundo, com a dimensão social e cultural em que vive. Em uma perspectiva mais fortemente fundamentada no existencialismo, pode-se afirmar que haveria uma contraposição à ideia de que há uma determinação original do homem dada por uma natureza seja biológica, social ou psíquica. Deste modo, a criança - ou mesmo o adulto - são capazes de "existir a existência que é a sua, descobrindo sua própria medida na relação entre os elementos que a constitui" (Feijoo, Protasio, \& Gill, 2015, p. 141).

Por outro lado, nas reflexões de Husserl (1935/1993) sobre a infância, temos uma compreensão da criança que também apontaria para um telos, assim como as teorias desenvolvimentistas. Segundo Shepherd (2006), para Husserl a criança não apresenta diferenças em relação ao adulto no que diz respeito às suas habilidades de percepção, contudo, notamos haver um ideal e um progresso a ser alcançado ao longo da infância para que a criança pudesse ser considerada como desperta para o mundo humano: o primeiro ato de empatia. Embora sua perspectiva seja fortemente calcada na compreensão da criança inserida no mundo, na relação com os outros, Husserl hesita entre uma explicação ontológica e uma explicação epistemológica sobre os modos pelos quais a criança compreende a si mesma como um "eu" em contraposição aos dados do mundo e aos outros (Allen, 1976; Freitas, 2015). Segundo Merleau-Ponty (2006), Husserl não resolve este problema. Mesmo em uma tão breve reflexão, podemos observar que o problema da compreensão da infância é complexo e a compreensão do que vem a ser uma criança não apresenta unidade nem mesmo na filosofia fenomenológica, com suas diferentes leituras.

Com o crescimento da abordagem fenomenológico-existencial em Psicologia, torna-se relevante compreender os modos pelos quais esta perspectiva tem apreendido e situado o problema da infância. Não raro, trabalhos que se propõem a estudar a temática lançam mão de outras perspectivas teóricas da psicologia no momento em que se torna necessário delimitar a compreensão da criança e do universo infantil.

Apesar da enorme contribuição que a perspectiva fenomenológica pode proporcionar ao estudo do tema, por oferecer instrumentos metodológicos que permitem um voltar-se ao mundo da experiência infantil, por meio da redução, não há trabalhos que mapeiem o modo como a psicologia fenomenológico-existencial tem abordado a temática, tornando o tema da criança e da infância um tanto nebuloso. A descrição de um panorama das publicações científicas referentes à infância no escopo da fenomenologia pode tanto servir como fonte de pesquisa para o aprofundamento do tema, revelando suas lacunas e as interpretações em uso, quanto de estímulo a outros pesquisadores, no sentido de serem ampliadas as possibilidades de compreensão da criança a partir de suas vivências próprias, destacando-se do ideal de adultez como preconcepção sobre o humano.

Diante dessas considerações, o presente trabalho tem como objetivo traçar um panorama das publicações científicas sobre o tema, por meio de uma revisão sistemática de literatura. Buscou-se entender como o ser criança tem sido compreendido a partir da perspectiva fenomenológica em psicologia e de que forma o tema está distribuído e tematizado nas publicações científicas.

\section{Método}

Foi realizada uma pesquisa de revisão sistemática de literatura com buscas de artigos nas seguintes bases de dados: Portal CAPES, PePSIC, SciELO e BVS Salud Bireme, com data final em fevereiro de 2017. A primeira busca foi realizada com os descritores "infância” e "fenomenologia", e a outra com os descritores "criança" e "fenomenologia”. Os artigos incluídos, segundo critério de inclusão, foram aqueles publicados em periódicos científicos. Foram excluídos os textos que não abordavam a infância ou qualquer temática relacionada a esta sob o viés da filosofia ou da psicologia fenomenológica, sendo 
que tal exclusão foi realizada a partir da análise dos resumos. Também foram excluídos artigos sem acesso via biblioteca institucional ou livre, bem como artigos repetidos em diferentes bases de dados.

Após a leitura integral dos artigos que restaram, buscou-se encontrar a definição de criança contida em cada um. As definições foram construídas a partir da leitura integral dos textos e extraídas de seu conteúdo. Muitos textos não apresentaram definições, mas apenas compreensões amplas sobre o tema. Todas as definições ou compreensões foram agrupadas em uma categoria nomeada "Compreensão do Ser Criança”, que tem por objetivo apresentar as possíveis descrições deste fenômeno sob o viés fenomenológico. Adverte-se que fenomenológico aqui é entendido de modo amplo e que em cada texto vincula-se diretamente à compreensão de cada autor ou grupo de autores. Deste modo, tal como é entendido no panorama brasileiro, frequentemente o viés fenomenológico inclui as perspectivas existencial e humanista em psicologia. Tal categoria foi dividida nas seguintes subcategorias, que expressam as compreensões apresentadas e discutidas nos próprios trabalhos analisados: Ser-no-mundo, Ser Histórico-social, Tendência Autoatualizante, Etapa do Desenvolvimento, Corporeidade, Irresponsabilidade do Para-si, Sujeito Ativo na Própria História e Urkind, ou criança originária.

As outras categorias de análise foram: Ano de Publicação, Idioma, Revista de Publicação, Área de Conhecimento, Método e Autores de Referência. Estas categorias foram escolhidas com o intuito de produzir um panorama amplo sobre os estudos do tema na área, identificando as tendências de compreensão, filiações e problemas pesquisados. Tal categorização foi realizada por pesquisadores diferentes. Posteriormente, uma revisão da primeira categorização dos dados foi executada, em conjunto, para que possíveis problemas e vieses quanto à classificação dos artigos em cada categoria fossem minimizados, uma vez que esta análise foi em um primeiro momento realizada por mais de uma pessoa.

\section{Resultados e Discussão}

Em uma primeira busca, realizada no portal PePSIC, foram encontrados três artigos, todos incluídos. No Portal CAPES, encontrou-se 181 resultados, com os descritores "infância" e "fenomenologia", e 85 com os descritores "criança" e "fenomenologia", dos quais 14 foram incluídos. Na busca no Portal SciELO, todos os artigos encontrados já haviam aparecido nos resultados obtidos via Portal CAPES. Por fim, no Portal da BVS Salud Bireme, foram encontrados 29 artigos com os descritores "infância" e "fenomenologia" e 159 com os descritores "criança" e "fenomenologia". Destes, cinco foram incluídos na pesquisa, sendo que dois foram excluídos por repetição, uma vez que já haviam sido encontrados no Portal CAPES e no PePSIC, restando três ao final. Após as buscas e a aplicação dos critérios de inclusão e exclusão, restou um total final de 20 artigos. Os resultados serão apresentados a partir das categorias de análise explicitadas na sessão do método.

\section{Ano de Publicação}

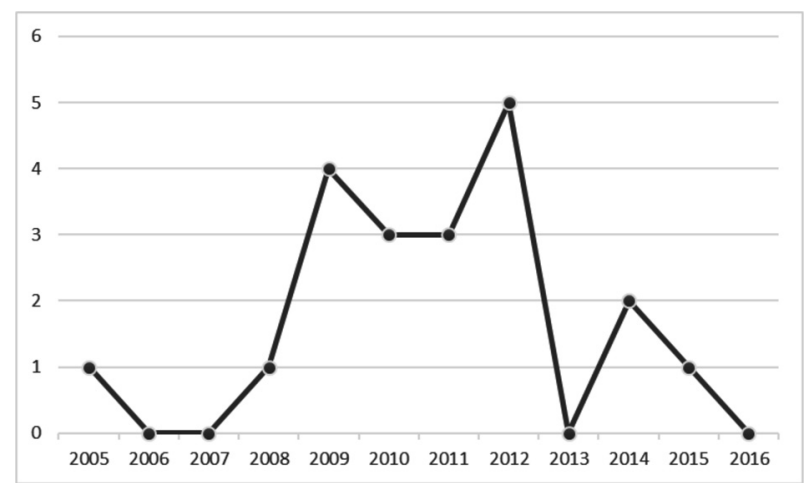

Figura 1: Número de publicações de artigos por ano.

Foram encontradas publicações sobre o tema apenas a partir do ano de 2005, inexistindo publicações anteriores a esta data, assim como em 2006 e 2007. Percebe-se que houve uma tendência de crescimento de publicações, especialmente depois de 2008, assim como aconteceu com outras temáticas também estudadas pela fenomenologia, especialmente a psicologia fenomenológica brasileira, tais como a temática da depressão (Holanda \& Santiago, 2013), da morte (Barbosa, Melchiori, \& Neme, 2011), e da corporeidade (Freitas, Bevilacqua, Castilhos, Michel, \& Pértile, 2015).

O pico de publicações dos últimos 12 anos concentra-se entre 2009 e 2012, com 15 produtos no período. Contudo, parece que o tema da infância não despertou tanto interesse depois de 2013, pois a partir deste ano apresenta-se uma queda significativa no número de publicações, mantendo-se uma média de uma publicação por ano até 2015, como exposto na Figura 1. Este quadro aponta uma escassez de produções sobre a infância e a criança do ponto de vista fenomenológico nos últimos anos. Uma pesquisa que investigasse outros tipos de produção, tais como livros, capítulos, teses e dissertações poderia contribuir para uma melhor avaliação desta tendência, descrevendo se nessas mídias essa tendência de diminuição se mantém ou não.

\section{Idioma de Publicação}

Dos artigos selecionados, 14 são em língua portuguesa e seis em língua espanhola, o que provavelmente se deve às bases de dados nas quais foi realizada a pesquisa, já que a maioria delas se situam em países da América Latina. De qualquer modo, ressalta-se que as produções brasileiras se destacam diante daquelas de outros países da América Latina. 


\section{Revista}

Dentre os dados encontrados, há uma dispersão das publicações nas mais variadas revistas, tendo apenas uma revista aparecido mais de uma vez, a saber, a Revista da Abordagem Gestáltica, com duas publicações. Este dado talvez demonstre que mesmo temas especializados hoje não necessariamente são publicados em revistas com um escopo específico dentro de uma grande área. Contemporaneamente, frente à facilidade de acesso a publicações científicas via internet, a comunicação científica aumentou e seu acesso foi simplificado. Para se comunicar com seus pares basta estar na rede, em uma publicação científica open access e não necessariamente em uma revista com alto nível de especialização, ou seja, não é preciso publicar em uma revista de fenomenologia para se falar sobre fenomenologia. Por outro lado, quando são contabilizadas e analisadas as áreas do saber das revistas, há uma concentração de publicações de artigos em psicologia e filosofia, sendo que psicologia conta com 11 publicações, mais do dobro da filosofia.

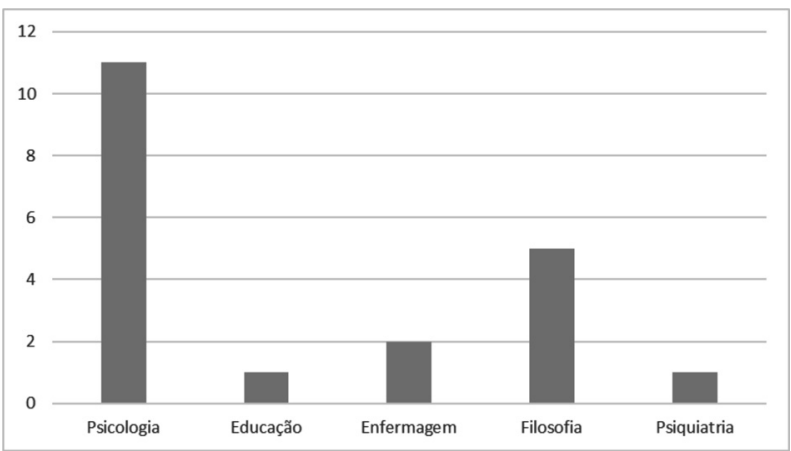

Figura 2: Número de publicações de artigos por área de concentração da revista.

Não é surpreendente que revistas das áreas de psicologia e filosofia sejam as que mais publicaram artigos que apresentam compreensões de infância sob o viés fenomenológico. Isso talvez se deva ao fato de que a fenomenologia, como corrente filosófica, se relaciona à psicologia a partir de uma proximidade conceitual e formal (Holanda, 2009). Também é possível que outras áreas do conhecimento, de alguma forma vinculadas ao trabalho com crianças, tais como educação e saúde, recorram justamente às análises das abordagens da psicologia e da filosofia para tentar ampliar suas análises sobre a infância e a criança.

\section{4. Área de Conhecimento dos Artigos}

Além da área de concentração das revistas científicas, cada artigo se situa em uma área específica, frente à problemática que discute e apresenta. Verificou-se que o tema de discussão do artigo não necessariamente coincide com o escopo da revista. Há, por exemplo, artigos que discutem problemas filosóficos publicados em revista nomeadamente de psicologia. Em relação à área de conhecimento em que se situam os artigos, também a filosofia e a psicologia foram as áreas que mais publicaram sobre infância, criança e fenomenologia, com sete publicações de artigos de filosofia e nove de psicologia, como mostra a Figura 3. As áreas de conhecimento que apresentaram menos publicações são enfermagem, antropologia e educação.

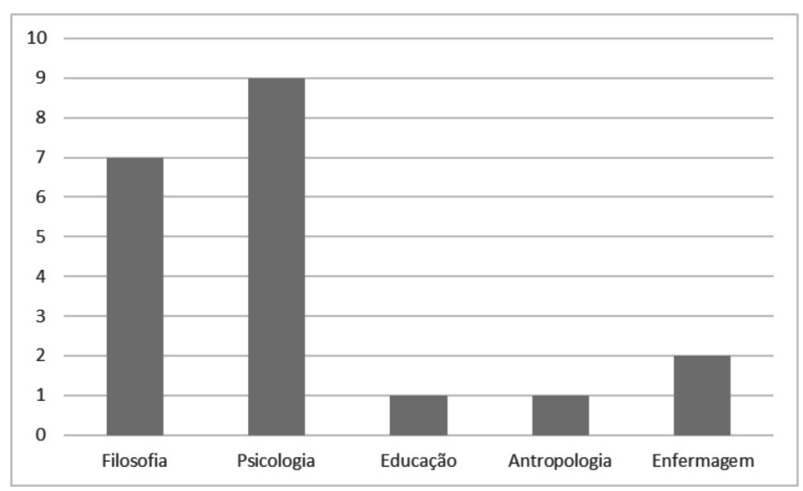

Figura 3: Número de artigos por área de conhecimento.

Reitera-se aqui, como possível explicação para o maior número de publicações sobre o tema analisado pertencer às áreas da psicologia e da filosofia, a proximidade conceitual e formal, mencionada por Holanda (2009), entre psicologia e fenomenologia, esta enquanto corrente filosófica. Por isso, o fenômeno da infância analisado pela fenomenologia interessa tanto à psicologia quanto à filosofia, afinal, "os entrelaçamentos entre Fenomenologia e Psicologia são mais estreitos do que a literatura tradicional aponta” (Holanda, 2009, p. 87). Talvez seja justamente por essas duas áreas serem historicamente interligadas e tradicionalmente se dedicarem à compreensão dos fenômenos humanos, que outras áreas não possuam a mesma propriedade de análise do tema, recorrendo à psicologia e à filosofia para uma possível compreensão do ser criança, assim, consequentemente, publicando menos sobre a temática.

\section{Método}

Dos 20 artigos selecionados, 14 se constituem como estudos teóricos e seis como relatos de pesquisa, todos com estudos qualitativos. A produção de estudos teóricos representa $60 \%$ da produção total de artigos, revelando uma necessidade da área em fomentar estudos que se voltem à experiência mesma da criança, tal como se propõe o método fenomenológico. Faz-se mister destacar que aqui consideramos teóricos os trabalhos sem delineamento de coleta de dados. Todos os estudos empíricos apresentam pesquisas com metodologias qualitativas, de acordo com o viés fenomenológico, que se interessa pelos fenômenos subjetivos da existência e do sentido.

Quando tentamos realizar uma análise mais aprofundada dos diferentes métodos qualitativos empregados, 
percebe-se uma grande variedade dos mesmos. Há duas referências ao método da "narrativa", sendo que uma delas explicita os procedimentos de análise até um determinado ponto, mas não os modos de interpretação, a outra referência apenas afirma utilizar tal método, sem explicitação de seus passos metodológicos. Há também uma referência ao "método fenomenológico de Merleau-Ponty", com descrição de passos metodológicos, uma referência ao método "fenomenológico-existencial de Martin Heidegger", que relata fazer uso dos passos metodológicos sugeridos por Martins e Bicudo, método este utilizado também por outro artigo que se utiliza da perspectiva Merleau-Pontyana. Há ainda um último estudo que apenas afirma utilizar o método "qualitativo à luz do referencial de Martin Heidegger", sem explicitar procedimentos. Percebe-se que da mesma forma que a fenomenologia-existencial (aqui tomada em sentido lato) abraça diferentes perspectivas e diferentes autores, também se fundamenta em diferentes metodologias de pesquisa. Embora o método de Martins e Bicudo já seja consagrado no Brasil, ele não é predominante nos trabalhos, assim como o também consagrado método fenomenológico de Giorgi, que nem mesmo aparece. No conjunto, o que se mostrou como mais significativo, foi a ausência de descrição dos procedimentos em um dos artigos e dos modos de análise em vários outros. Frequentemente, encontra-se uma descrição do método de maneira mais generalizada, explicitando mais o aspecto da qualidade do método fenomenológico do que do procedimento per se. Em alguns artigos, não há nem mesmo descrições completas sobre a coleta de dados, ou sobre a análise.

Este é um problema que deve ser compreendido de um modo mais abrangente e merece investigações posteriores de outros trabalhos com objetos diversos, especialmente no campo da Psicologia Fenomenológica. A descrição do que se faz na sessão metodológica é fundamental para a compreensão do modo pelo qual certos resultados são alcançados, correndo-se o risco de termos apenas produções que já estão pré-determinadas pelas teorias em jogo, ou que carecem de terem suas relações explicitadas, fragilizando os resultados. A produção de conhecimento exige explicitação dos métodos, inclusive em Fenomenologia. Nesta direção, é curioso observar que a Fenomenologia se consagra e frequentemente é, inclusive, definida como tal, a partir exatamente de seus fundamentos metodológicos rigorosos.

\section{Autores de Referência}

Quanto aos autores utilizados como referência na abordagem do tema, observa-se na Figura 4, que o autor mais utilizado foi Merleau-Ponty, em $40 \%$ das publicações, seguido por Heidegger e Husserl, com cada autor sendo referenciado em 15\% delas. Dois textos se utilizam de diversos autores, a saber, um sobre clínica psicológi- ca infantil, perfazendo uma revisão de autores diferentes do existencialismo (Feijoo, 2011) e outro pesquisando sobre a realidade dos índios Jenipapo-Kanindé (Pinheiro \& Frota, 2009), lançando mão de referências também de outras áreas. Todos os outros autores (Sartre, Rogers, Fink e Schütz), foram referenciados em apenas um texto cada.

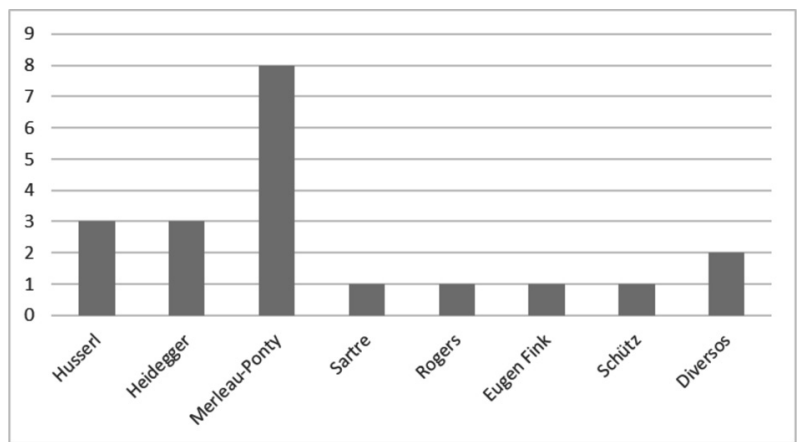

Figura 4: Número de artigos por autores de referência.

A alta incidência de Merleau-Ponty como autor de referência pode ser explicada pelas características de seus estudos sobre a infância, que interessam tanto aos educadores como aos filósofos e psicólogos (Rezende, 1990). Destaca-se também que até pouco tempo, Merleau-Ponty era o único autor da fenomenologia que tinha uma obra traduzida para o português sobre o tema, a saber, uma coletânea de dois volumes sobre seus cursos na Sorbonne, publicada no Brasil pela primeira vez pela editora Papirus no ano de 1990, mais tarde republicada pela Martins Fontes como Psicologia e Pedagogia da Criança, em 2006. A forma como o autor concebe a fenomenologia é original, na medida que entende o fenômeno humano como ser-no-mundo, opondo-se aos paradigmas subjetivistas e à concepção naturalizada das ciências humanas sobre a criança, que estabelecem um padrão de estudo em que ela é vista como objeto ou como apenas um dado de análise. Nessa perspectiva, apesar de conservar seus estudos dentro do escopo da fenomenologia, o filósofo mantém interlocução com autores tais como Husserl, Heidegger, Goldstein, Hegel e Marx. Assim, seus estudos concentram variadas dimensões, como a fenomenológica, a existencial, a estrutural, a transcendental e a dialética, advindas desses autores (Rezende, 1990). O fácil acesso à sua obra, aliado à amplitude e complexidade de seu pensamento, possibilita uma análise ampla do fenômeno da infância, o que pode justificar a frequência com que Merleau-Ponty é tido como referência para a compreensão e o estudo da criança.

Os textos que o utilizam como referência, apresentam as seguintes definições de criança: Sujeito ativo na própria história (um texto), criança como ser Histórico-social (um texto), Ser-no-mundo e Corporeidade (cinco textos cada). A maior incidência de compreensões da criança como ser-no-mundo e corporeidade encontram-se em plena consonância com as obras e pensamento do autor. Nota-se que há textos que compreendem a criança a partir 
de mais de uma categoria, por exemplo, ser-no-mundo e corporeidade, apontando para a complexidade do tema, assim como para a própria concepção de humano em fenomenologia que abarca dimensões múltiplas do existir.

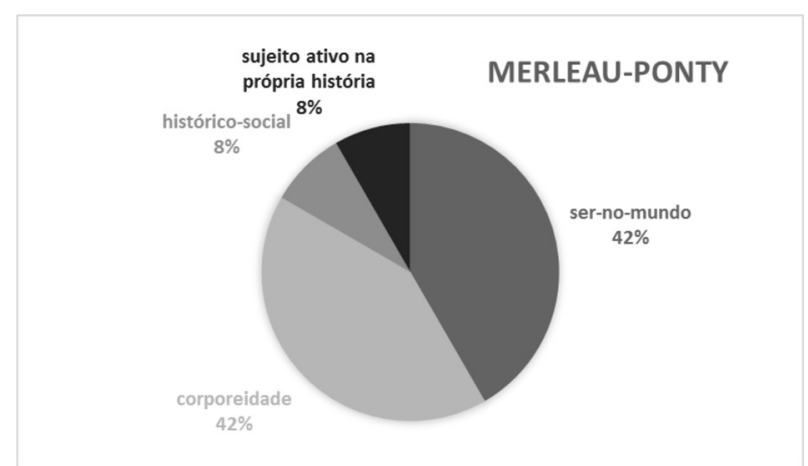

Figura 5: Compreensões de ser criança encontradas nos textos que apresentam Merleau-Ponty como autor de referência.

Nos textos que apresentam Heidegger como referência, todas as compreensões sobre ser criança são que esta se constitui como ser-no-mundo, em coerência absoluta com sua filosofia. Nos três textos que se sustentam nas ideias de Husserl, encontramos compreensões sobre ser criança completamente diferentes entre si. Em um deles, a infância é percebida como uma etapa do desenvolvimento, em um segundo, como corporeidade e, por último, como Urkind ou criança originária, em conformidade com o manuscrito de Husserl sobre a infância (Husserl, 1935/1993). Talvez essa dispersão se deva à escassez de trabalhos e de traduções de textos do autor sobre o tema em português.

\section{Compreensão de Ser Criança}

Ao serem analisadas as definições ou compreensões de criança apresentadas nos artigos, foram extraídas oito subcategorias que apontam para os diferentes modos pelos quais a criança é teoricamente apresentada ou filosoficamente problematizada. As subcategorias definidas foram: Ser-no-mundo, Ser Histórico-social, Tendência Autoatualizante, Etapa do Desenvolvimento, Corporeidade, Irresponsabilidade do Para-si, Sujeito Ativo na Própria História e Urkind.

Conforme a Figura 6, percebe-se que a maioria dos artigos considera a criança como Ser-no-mundo (42\%), seguido de Corporeidade (23\%). Apenas um artigo não continha descrição alguma sobre o que é ser criança. Como dito anteriormente, em alguns artigos o ser criança foi descrito de mais de um modo, como por exemplo, "ser no mundo" e "corporeidade", por isso temos uma frequência total de 26 descrições diferentes de criança e não apenas 20. A seguir serão analisadas cada uma delas em particular e seus sentidos.

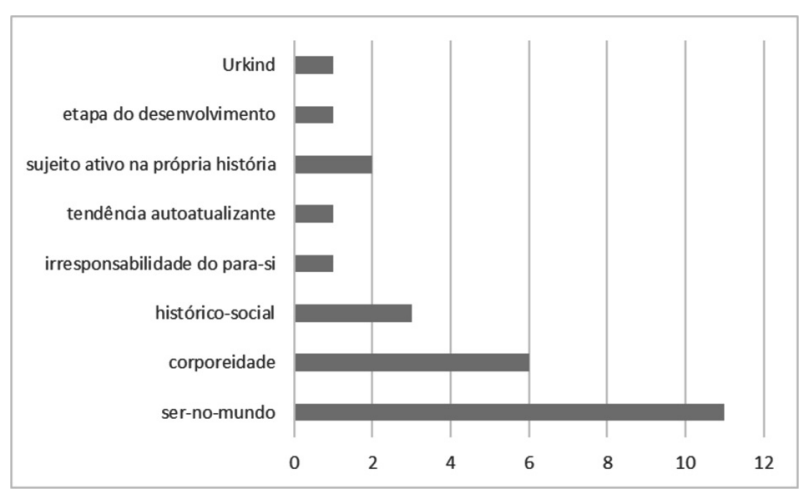

Figura 6: Classificação dos artigos por compreensão de criança.

\subsection{Ser-no-mundo}

A compreensão mais encontrada, presente em 11 artigos (42\%), foi a descrição da criança a partir de seu caráter de ser-no-mundo. Com maior incidência de textos que se utilizam de Merleau-Ponty (46\% dos textos) e Heidegger (27\%) como referências, essa foi uma compreensão de ser criança que apareceu também em três outros trabalhos: um que se fundamenta em Eugen Fink (Holzapfel, 2011) e em outros dois que discutiram a questão a partir de diversos autores diferentes (Feijoo, 2011; Pinheiro, \& Frota, 2009).

Afirmar que a criança é ser-no-mundo é entender que sua existência não difere da do adulto, pois ambos possuem a mesma condição do existir. Ou seja, a criança não é alguém que precisaria de um desenvolvimento prévio para viver sua condição de existente. Não é a criança, afinal, alguém a quem falta alguma coisa, portanto deve ser compreendida como qualquer outro existente. Apresentaremos alguns exemplos abaixo.

A criança como ser-no-mundo aparece, por exemplo, em Buss-Simão (2009) e em Siqueira, Santos, Gomez, Saltareli e Sousa (2015), quando afirmam que para Merleau-Ponty nada faltaria à criança em comparação ao adulto. Assim também o defende Quintiliano (2014), demonstrando que a criança aprende e se desenvolve de uma maneira que contém as raízes de toda atividade humana madura. A infância se caracterizaria por uma possibilidade constante de passagem entre os diferentes modos de relação com o mundo: ser criança é ser abertura ao possível.

Telles (2014), ao discorrer sobre infância na fenomenologia de Merleau-Ponty, com foco na psicologia e na educação, apresenta a compreensão da criança como sujeito ativo na própria história e como ser-no-mundo. A autora caracteriza o fenômeno da infância como atrelado às questões da cultura e da liberdade da criança, sendo esta, alguém que se posiciona no mundo, capaz de aprender a assumir as consequências de seu posicionar-se. As experiências infantis, assim, não poderiam ser homogeneizadas, uma vez que cada criança tem seu ponto de vista sobre o mundo, do mesmo modo tal como ocorre com o adulto. 
Melo e Valle (2010) em uma perspectiva heideggeriana, afirmam em seu artigo que a criança, ao brincar, revela seu existir de modo próprio. Melo et al. (2012) afirmam que a criança como ser-no-mundo encontra-se no contexto hospitalar sob a tutela de outrem, precisando, portanto, ser tratada de modo holístico e não apenas a partir de sua condição médico-hospitalar. O pensamento de Heidegger também é utilizado como fundamento teórico para o artigo de Feijoo, Gill e Protasio (2012), que se propõem a investigar a história de Victor de Aveyron - o menino selvagem - a fim de buscar elementos para discutir o modo pelo qual a existência humana se constitui - não se desenvolve. As autoras consideram a experiência infantil a partir de uma hermenêutica fenomenológica e existencial, compreendendo a possibilidade de se pensar a criança como um existir que tem em sua constituição o caráter de indeterminação e consequente liberdade. As autoras discutem a cognição da criança a partir de sua co-originaridade com o mundo, desconsiderando as hipostasias, seja ambientalista ou inativista. Logo, estremecer, sugar e chorar, por exemplo, são atos, e, como tal, são intencionais. Os fenômenos da intencionalidade já se revelariam na primeira situação, na qual se encontra um ser-aí em sua entrega ao mundo, inicialmente desvalida e indeterminada. $\mathrm{O}$ texto faz referência às reduções fenomenológicas, exercício incessante para alcançar o fenômeno, deixando para trás todas as pressuposições sobre o mesmo.

\subsection{Corporeidade}

A corporeidade foi uma forma de compreensão do ser criança que apareceu também com muita frequência, em seis artigos (23\%), mas de modos diversos. Verissimo (2011), por exemplo, referencia a psicogênese de Merleau-Ponty para defender que a infância jamais é radicalmente liquidada e a objetivação nunca é acabada, pois o corpo permanece ocupando um papel central em nossa relação com o mundo. Em seus dois artigos, Verissimo (2011; 2012) destaca o papel da corporeidade como engajamento no mundo, como enraizamento para o sentido. Assim também é a compreensão de Fierro (2012). Por outro lado, também se fundamentando em Merleau-Ponty, Buss-Simão (2009), entende a dimensão corporal da criança como um produto social e histórico, e não apenas biológico, todavia, defende que a dimensão corporal também é dotada de intencionalidades e significados, confirmando a ausência de passividade da criança e o aspecto marcante do corpo como Leib em Merleau-Ponty.

Já a corporeidade em Rizo-Patron (2010) é compreendida a partir do pensamento de Husserl. O autor afirma que o recém-nascido já tem um instinto orientado, horizontes perceptivos, adquiridos pela relação com a mãe. Tal perspectiva está em consonância com a concepção de Husserl sobre a gênese pré-reflexiva da intersubjetividade como hylé, defendido em seu manuscrito de 1935
(Husserl, 1935/1993). A descoberta de si aconteceria, então, no campo das sensações e cinestesias, por meio do reconhecimento do próprio corpo, o qual é originalmente indiferenciado do corpo da mãe.

\subsection{Ser histórico-social}

Três artigos (11\%) abordam a criança como ser histórico-social. Pinheiro e Frota (2009) discutem a infância como uma categoria socialmente construída, vivenciada de forma singular em cada momento da história e nas diferentes sociedades e culturas. As autoras buscam a partir de diversos autores, conceber a infância fora da lógica desenvolvimentista, onde a criança é ativa no processo de construção das relações sociais e na constituição dos sentidos do mundo. De modo semelhante, Yoseff Bernal (2005), em consonância com os trabalhos de Schütz, que usa como fundamentação teórica, concebe a criança como ativa desde o nascimento e que seu "psiquismo" se constituiria na interação com os outros. A perspectiva de o que é ser criança para o autor dependeria da concepção de cada sociedade. Por ser um texto que busca uma aproximação entre a perspectiva fenomenológica e a cultural, por meio da fenomenologia de Schütz, justifica-se um viés mais cultural para a compreensão da infância.

Já em Melo e Moreira (2008), a despeito de apresentarem uma perspectiva Merleau-Pontyana, entendem a criança como ser histórico-social. De acordo com sua análise, a sociedade pós-moderna, com as imposições da mídia e do consumo, torna as crianças cada vez mais próximas do mundo adolescente e adulto, fazendo com que as experiências da infância praticamente desapareçam resultando em uma adolescência prolongada, em uma relação de determinação com o ser-criança. Contudo, vale destacar que embora a perspectiva fenomenológica considere o mundo circundante extremamente relevante para a constituição humana, a cultura teria um papel menos determinante do que em uma perspectiva cultural, constituindo-se como horizonte e não como causa de determinação.

\subsection{Sujeito ativo na própria história}

A compreensão da criança como sujeito ativo na própria história foi encontrada em dois artigos (8\%). No artigo de Campos e Cury (2009), as autoras refletem sobre a concepção de infância na fenomenologia ao demonstrar a potencialidade de encontros terapêuticos com crianças. Assim, partem da perspectiva teórica da Psicologia Humanista para caracterizar o modo de ser da criança em encontros terapêuticos em uma creche. Defendem a capacidade das crianças em assumir a iniciativa pela procura espontânea por uma relação de ajuda psicológica.

Rogers, embora não seja um autor da Fenomenologia, parece ter sido usado nesse artigo de Campos e Cury (2009) por ser o criador da Abordagem Centrada na Pessoa, que, 
de algum modo, se aproxima da ideia da fenomenologia de entender a criança como um alguém capaz de tomar decisões em sua relação com o outro e com o mundo, exercendo sua condição de existência da mesma forma que o adulto. Fundamentando-se nos princípios humanistas de autonomia, apresenta-se a criança como uma pessoa aberta a tornar-se ela mesma e a viver de modo existencial, ou seja, pronta à experiência. Dessa forma, para Rogers, o ser humano encontra-se em um processo contínuo e constante de atualização rumo à autonomia do ser.

Telles (2014), entende que o fenômeno da infância, pensado a partir de Merleau-Ponty, se caracteriza atrelado às questões da cultura e da liberdade da criança, que se constitui como alguém que se posiciona no mundo. Ela é no mundo e se relaciona da forma que lhe é possível. Segundo a autora, as experiências infantis não poderiam ser homogeneizadas, uma vez que cada criança é existência, assim como os adultos.

\subsection{Tendência autoatualizante}

Um único artigo apenas define a tendência autoatualizante como uma característica presente na criança. Campos e Cury (2009), a partir do referencial teórico da psicologia humanista de Rogers, partem do princípio de que todo ser humano tem a capacidade de compreender-se a si mesmo e de resolver seus problemas de modo suficiente para alcançar a satisfação. Tal potencialidade é o que Rogers denomina de tendência autoatualizante, que seria, segundo as autoras, a responsável por conduzir-nos na direção do crescimento, inclusive as crianças, que são capazes de assumir a iniciativa pela procura espontânea por uma relação de ajuda psicológica, bem como de comunicar sentimentos a respeito de si mesmas. Dessa maneira, as autoras consideram a riqueza do mundo infantil, o qual é pleno de significados e sentimentos expressos de forma direta e espontânea. Portanto, as crianças também apresentariam a tendência autoatualizante e seriam seres humanos dignos de valorização e com potencial para o crescimento.

\subsection{Etapa do desenvolvimento}

Um único artigo classifica a infância como etapa do desenvolvimento. Ortega (2010) discute a temporalidade na melancolia, colocando a infância como uma etapa do desenvolvimento na constituição do adulto, na qual a criança depende de seus cuidadores para seu crescimento, revelando um olhar desenvolvimentista - que parece ir contra a proposta de investigar a experiência infantil por meio do método fenomenológico.

\subsection{Irresponsabilidade do para-si}

Somente o artigo de Campos, Alt e Ewald (2009), compreende a criança como irresponsabilidade do para-si, pois é também o único a fundamentar o trabalho em Sartre. Ao analisar o conto "A infância de um chefe", de Sartre, as autoras caracterizam a concepção de infância do filósofo por meio da linguagem literária. A infância seria a fase decisiva onde se modelam preconceitos insuperáveis na tentativa da criança de desempenhar o papel social que os adultos lhe impõem. A infância representaria a fase do mundo pronto, do constituído, da irresponsabilidade do para-si, que sendo "insuficiência de ser", apoia-se na definição de mundo dada pelos adultos para poder se colocar perante o vazio da existência. Um momento crucial do processo de constituição de si na criança seria quando vislumbra que suas respostas com um sentido definido vacilam e não pode mais recorrer aos modelos absolutos fornecidos pelos adultos: ela tem que decidir. Esse momento questionador da criança seria um momento de constituição de autonomia, quando começa a diferenciar o modo de ser das coisas e o da realidade humana.

\subsection{Urkind}

O artigo de Vargas Bejarano (2012) consiste em uma análise do artigo Filosofia como ciência rigorosa de Husserl. O autor entra em consonância com as reflexões do filósofo sobre a infância como um período da vida originária, determinante da gênese do eu e da relação entre o eu e o mundo, um passado presente que fala de uma experiência ante-predicativa do mundo tal como descritas no manuscrito de 1935. Husserl neste manuscrito denomina uma existência da criança ainda originária como Urkind, de onde a denominação desta categoria. Destaca-se que este é um texto em espanhol, mostrando uma lacuna de publicações sobre esta questão em português.

\section{Considerações Finais}

Com este estudo, procuramos descrever um panorama de como as publicações científicas em Fenomenologia entendem as dimensões do que é ser criança e do que é viver a infância. Nos dados da presente pesquisa, notou-se que nos últimos anos houve um decréscimo de publicações sobre o tema, questão que deve ser estudada posteriormente com trabalhos que levem em conta outros tipos de produção científica, tais como livros, teses e dissertações, para verificar se a tendência se repete também nestes veículos.

Constatou-se, no presente trabalho, que os estudos empíricos são por vezes precários na descrição dos métodos e metodologias empregados, conduzindo a questões sobre a pesquisa fenomenológica que ultrapassam o escopo do presente estudo, contudo, assevera-se a necessidade da área, especialmente a Psicologia Fenomenológica, pelo seu fundamento e identidade com um método rigoroso, debruçar-se sobre tal discussão. 
Dentre os autores utilizados como referenciais teóricos, Merleau-Ponty foi o que apareceu em mais artigos, demonstrando a enorme contribuição do autor para uma fenomenologia da criança. Destacaram-se sua oposição aos paradigmas subjetivistas e sua originalidade ao abordar a infância, além de sua ampla abordagem do tema, sempre dialogando com diversos autores ao realizar seus estudos. A riqueza do seu pensamento não apenas contribui para a sua maior incidência como autor referenciado, mas também por ser percebida quando da análise das diferentes concepções de infância que se sustentam a partir de sua obra. Por outro lado, nota-se a escassez de trabalhos que se fundamentem em Husserl, referência primeira da fenomenologia, apontando para uma lacuna deste tipo de reflexão na área que talvez tenha relação com a escassez das traduções de sua obra, bem como o difícil acesso às mesmas.

No presente trabalho manteve-se uma perspectiva ampla no que se considera como fenomenologia, deixando a cargo dos próprios autores a denominação e determinação do campo, haja vista a diversidade de filiações que encontramos, especialmente no Brasil. Apesar das diferentes perspectivas e da variedade de autores encontrados, conclui-se que podemos delimitar basicamente duas perspectivas sobre a infância nos textos analisados. A primeira compreende a criança a partir de uma noção desenvolvimentista, mais ou menos determinada, seja por um telos histórico ou biológico, por vezes não tão clara para os próprios autores que as utilizam. A segunda perspectiva, mais fundamentalmente existencial, considera a criança em seu caráter existencial, que não difere sob esse aspecto do adulto, contendo em si as raízes de toda atividade humana. Apesar de a segunda perspectiva ter apresentado uma maior incidência, ressalta-se que em certa medida, mesmo as perspectivas que tendem para uma compreensão desenvolvimentista falam da criança como alguém que não é puro efeito, mas que constitui os sentidos do seu existir ou mesmo como alguém ativo diante de seu meio e em suas relações.

Conclui-se que o tema da infância na fenomenologia merece atenção especial dos pesquisadores, já que pode contribuir para uma visão crítica a respeito das dimensões do que é ser criança nos mais variados contextos: educacional, clínico e da saúde. Torna-se necessário um maior investimento nas publicações sobre este tema, com a finalidade de divulgar essa perspectiva sobre a criança e de proporcionar o desenvolvimento de práticas que levem em consideração o ser-criança como alguém que não se define pela falta ou pela incompletude, mas que, com suas particularidades, vive plenamente sua condição de existente, assim como o adulto.

\section{Referências bibliográficas (Obs.: Referências} precedidas por asterisco fazem parte da revisão)

Allen, J. (1976). A husserlian phenomenology of the child. Journal of phenomenological psychology, 6, p. 164-179. doi: 10.1163/156916276X00052

Barbosa, C. G., Melchiori, L. E., \& Neme, C. M. B. (2011). Morte, família e a compreensão fenomenológica: revisão sistemática de literatura. Psicologia em Revista, 17, 363-377. Recuperado de http://pepsic.bvsalud.org/scielo.php?script=sci_art text\&pid $=$ S1677-11682011000300003

*Buss-Simão, M. M. (2009). A dimensão corporal: implicações no cotidiano da educação da pequena infância. Revista internacional de investigacion en educacion, 2, 129-140. Recuperado de http://revistas.javeriana.edu.co/index.php/MAGIS/article/viewFile/3404/2591

${ }^{*}$ Campos, A. P. S., \& Cury, V.E. (2009). Atenção psicológica clínica: encontros terapêuticos com crianças em uma creche. Paidéia, 19, 115-121. doi: 10.1590/S0103-863X2009000100014

${ }^{*}$ Campos, C. M., Alt, F., \& P. Ewald, A. (2009). Interrelação filosófico-literária do pensamento de Sartre: bases para uma psicologia fenomenológica do eu. Revista da abordagem gestáltica, 15, 126-132. Recuperado de http://pepsic. bvsalud.org/scielo.php?script=sci_arttext\&pid=S1809$-68672009000200008 \& \operatorname{lng}=\mathrm{pt} \& \operatorname{tlng}=\mathrm{pt}$

*Feijoo, A. M. L. C. (2011). A clínica psicológica infantil em uma perspectiva existencial. Revista da abordagem gestáltica, 17(2), 185-192. Recuperado de http://pepsic.bvsalud.org/scielo.php?script=sci arttext\&pid=S1809-68672011000200009

*Feijoo, A. M. L. C., Gill, D., \& Protasio, M. M. (2012). Uma investigação do ser-aí do menino selvagem à luz do pensamento heideggeriano. Psico-USF, 17, 225-232. doi: 10.1590/ S1413-82712012000200006

Feijoo, A. M. L. C., Protasio, M. M., \& Gill, D. (2015). Considerações sobre o deenvolvimento infantil em uma perspectiva existencial. In A. M. L. C. Feijoo, \& E. L. Feijoo (Orgs.), Ser Criança: uma compreensão existencial da experiência infantil (p. 115-164). Rio de Janeiro, RJ: Edições IFEN.

*Fierro, M. (2012). El desarrollo conceptual de la ciencia cognitiva. Parte II. Revista colombiana de psiquiatría, 41, 185-196. Recuperado de http://www.scielo.org.co/scielo. php?script $=$ sci_arttext\&pid $=$ S0034-74502012000100013

Freitas, J. L. (2015). A criança sob o olhar fenomenológico: O Despertar do Mundo-da-Vida. In A. M. L. C. Feijoo, \& E. L. Feijoo (Orgs.), Ser Criança: uma compreensão existencial da experiência infantil (p. 35-52). Rio de Janeiro, RJ: Edições IFEN.

Freitas, J. F., Bevilacqua, C., Castilhos, J. C., Michel, L. H., \& Pértile, C. (2015). Corpo e psicologia: Uma revisão da produção científica brasileira na primeira década dos anos 2000. Psicologia em Revista, 21, 66-86. doi: 10.5752/P.1678-9523.2015V21N1P66

Holanda, A. F. (2009). Fenomenologia e psicologia: diálogos e interlocuções. Revista da abordagem gestáltica, 15, 87-92. Recuperado de http://pepsic.bvsalud.org/scielo.php?script $=$ sci arttext\&pid $=$ S1809-68672009000200002\&lng $=p t \& t \operatorname{lng}=p t$ 
Holanda, A. F., \& Santiago, A. (2013). Fenomenologia da depressão: uma análise da produção acadêmica brasileira. Revista da abordagem gestáltica, 19, 38-50. Recuperado de http://pepsic.bvsalud.org/scielo.php?script=sci_arttext\&pi $\mathrm{d}=$ S1809-68672013000100006

*Holzapfel, C. (2011). Fenomenos existenciales fundamentales de Eugen Fink: juego y muerte. Revista de filosofia, 67, 201-214. doi: 10.4067/S0718-43602011000100013

Husserl, E. (1993). L'enfant. La première Einfühlung. Alter, 1, 265-270. (Tradução de N. Depraz). (Manuscrito original de 1935).

*Melo, A. K. S., \& Moreira, V. (2008). Fenomenologia da queixa depressiva em adolescentes: um estudo crítico-cultural. Aletheia, 27, 51-64. Recuperado de http://pepsic.bvsalud. org/scielo.php?script=sci_arttext\&pid $=$ S1413 03942008000100005

*Melo, H. C., Araújo, S. E. G., Veríssimo, A. V. R., Santos, V. E. F. A., Alves, E. R. P., \& Souza, M. H. N. (2012). O ser-enfermeiro em face do cuidado à criança no pós-operatório imediato de cirurgia cardíaca. Escola Anna Nery, 16, 473-479. doi: 10.1590/S1414-81452012000300007

*Melo, L. L., \& Valle, E. R. M. (2010). A Brinquedoteca como possibilidade para desvelar o cotidiano da criança com câncer em tratamento ambulatorial. Revista da escola de enfermagem da USP, 44, 517-525. doi: 10.1590/S008062342010000200039

Merleau-Ponty, M. (2002). Palestras. (A. Morão, Trans.) Lisboa: edições70.

Merleau-Ponty, M. (2006). Psicologia e Pedagogia da Criança (Tradução de I. C. Benedetti). São Paulo: Martins Fontes.

*Ortega, J. G. F. (2010). Experiencia de acabamiento del pasado y pulsos vitales del sujeto: Aproximación fenomenológica al psicoanálisis de la depresión melancólica. Diánoia, 55, 127-152. Recuperado de http://www.scielo.org.mx/scielo. php?script $=$ sci_arttext\&pid $=$ S0185-24502010000100006

*Pinheiro, S. L., \& Frota, A. M. M. C. (2009). Uma compreensão da infância dos índios Jenipapo-Kanindé a partir deles mesmos: um olhar fenomenológico, através de narrativas e desenhos. Estudos e Pesquisas em Psicologia, 9, 724-759. Recuperado de http://www.revispsi.uerj.br/v9n3/artigos/ pdf/v9n3a12.pdf

*Quintiliano, A. (2014). Ontologia fenomenológica e educação: uma leitura de Merleau-Ponty. Childhood \& philosophy, 10, 357-381. Recuperado de http://www.e-publicacoes.uerj.br/ index.php/childhood/article/view/20683/15009

Rezende, A. M. (1990). Apresentação. In: M. Merleau-Ponty. Merleau-Ponty na Sorbonne: resumo de cursos: filosofia e linguagem (p. 11-15). Campinas, SP: Papirus.

*Rizo-Patron, R. (2010). Diferencia y otredad desde la fenomenología de Husserl. Arete, 22, 87-106. Recuperado de http://www.scielo.org.pe/scielo.php?pid=S1016-913 X2010000100005\&script $=$ sci arttext

*Siqueira, H. B. O. M., Santos, M. A., Gomez, R. R. F., Saltareli, S., \& Sousa, F. A. E. F. (2015). Expressão da dor na criança com câncer: uma compreensão fenomenológica. Estudos de Psicologia (Campinas), 32, 663-674. doi: 10.1590/0103166X2015000400009

Shepherd, D. (2006). Contra deficient child perception: a husserliana analysis. Childhood \& Philosophy, 2, 115-125. Recuperado de http://www.e-publicacoes.uerj.br/ojs/index.php/ childhood/article/view/20491/14817

Souza, S. J. (1996). Re-significando a psicologia do desenvolvimento: uma contribuição crítica à pesquisa da infância. In S. Kramer, \& M. I. Leite (Orgs.), Infância: fios e desafios da pesquisa (p. 39-55). Campinas, SP: Papirus.

*Telles, T. C. B. (2014). A infância na fenomenologia de Merleau-Ponty: contribuições para a psicologia e para a educação. Revista do NUFEN, 6(2), 4-14. Recuperado de http://pepsic.bvsalud.org/scielo.php?script=sci_arttext\&pid $=\mathrm{S} 2175-25912014000200002$

*Vargas Bejarano, J. C. (2012). Tres propuestas para renovar el programa de La "Filosofia como ciencia rigurosa" de 1911. Praxis Filosófica, 34, 39-60. Recuperado de http://www. scielo.org.co/scielo.php?script $=$ sci arttext\&pid $=$ S0120$-46882012000100003 \& \operatorname{lng}=$ en\&nrm $=$ iso\&tlng $=$ es

*Verissimo, D. S. (2011). Merleau-Ponty e a psicologia infantil: análises da psicogênese em Wallon. Psicologia em estudo, 16, 459-469. doi: 10.1590/S1413-73722011000300013

*Verissimo, D. S. (2012). No limiar do mundo visível: a noção de esquema corporal nos cursos de Merleau-Ponty na Sorbonne. Psicologia USP, 23, 367-394. doi: 10.1590/S010365642012005000006

*Yoseff Bernal, J. J. (2005). El estudio de la infancia desde la psicología cultural: un encuentro de perspectivas. Avances en Psicología Latinoamericana, 23, 63-76. Recuperado de http://www.redalyc.org/articulo.oa?id=79902306.

Elisa Smile Teixeira de Oliveira - É Graduanda de Psicologia da Universidade Federal do Paraná. E-mail: elisa2312@gmail.com

Amanda Acco Rosa - É Graduanda de Psicologia da Universidade Federal do Paraná. E-mail: amandaacco@gmail.com

Joanneliese de Lucas Freitas - É Doutora em Psicologia pela Universidade de Brasília, Mestre em Psicologia do Desenvolvimento pela Universidade de Brasília. Integrante dos Grupos de Pesquisa do CNPq: Laboratório de Psicopatologia Fundamental (UFPR), Fundamentos fenomenológicos-existenciais de diferentes práticas em psicologia (UERJ), LIEPPFEX - Laboratório Interinstitucional de Estudos e Pesquisa em Psicologia, Fenomenologia e Existencialismo (UEM).E-mail: joanneliese@gmail.com

Recebido em 20.02.17 Aceito em 12.04.17 